\title{
Investigating the use of milk fatty acids to detect dietary changes: a comparison with faecal analysis in Antarctic fur seals
}

\author{
I. J. Staniland*, D. W. Pond \\ British Antarctic Survey, NERC, High Cross, Madingley Road, Cambridge CB3 0ET, UK
}

\begin{abstract}
We compared the use of fatty acid signature analysis with results from traditional faecal methods using milk samples and enemas concurrently collected from 8 female Antarctic fur seals Arctocephalus gazella foraging from Bird Island, South Georgia. The seals were serially sampled throughout the 1998/1999 breeding season, with collections taken after every foraging trip when possible. The total lipid content of the milk increased throughout the season. A general linear model using 4 principal components showed that it was the point within the breeding season at which a milk sample was collected that had the biggest influence on its fatty acid composition. There were also significant differences in the milk composition of individual seals. However, the results of faecal analysis, which are themselves subject to potential biases, were not correlated with the relative amounts of individual fatty acids. It has been suggested that seasonal changes in the milk fatty acids, previously observed in the same population of seals, are a result of increased consumption of fish. We found no evidence of this in the faecal material and suggest that the seasonal variability may be a result of changes in the fatty acid composition of the seals' main prey (krill), or because of the changing needs of the developing pups. This study highlights the need for comprehensive testing of milk fatty acid signature analysis before the full potential of this technique can be realised.
\end{abstract}

KEY WORDS: Antarctic fur seal · Arctocephalus gazella · Fatty acid · Milk · Diet · Seasonal variation · Individual variation · South Georgia

\section{INTRODUCTION}

There is great importance in determining the diets of top marine predators, not only because of their impact on prey species and potential competition with fisheries (McConnell et al. 1999, Gremillet et al. 2000, Rindorf et al. 2000), but also because they are increasingly being used to monitor ecosystems (Boyd \& Murray 2001, Thompson \& Ollason 2001). This top-down approach has used foraging behaviour and diet to estimate the distribution and abundance of prey species, factors that can be difficult and costly to measure directly (Cherel \& Weimerskirch 1995, Rodhouse et al. 1996).

Traditionally, because direct observation is usually impossible, the diet of top marine predators has been determined through techniques such as stomach lavage or faecal analysis. Remains resistant to digestion, such as otoliths, bones, exoskeletons and beaks, are used to resolve prey consumption using identification keys (Pierce \& Boyle 1991). Whilst this technique has proved invaluable, it is subject to a number of biases and limitations. The assumption that prey remains found in recovered material are representative of the prey ingested can be broken because of differential rates of erosion, retention and digestion (Harvey 1989, Tollit et al. 1997, Staniland 2002). Importantly, in species for which foraging trips last for a large number of days, land-based collections may only represent the prey consumed during recent feeding events, and may be biased towards prey caught near the haulout site (Helm 1984). 
Amongst the alternative methods, fatty acid signature analysis, commonly used within plankton communities (e.g. Graeve et al. 2002, Reuss \& Poulsen 2002), is increasingly being used to study higher trophic relationships (Raclot et al. 1998, Hooker et al. 2001, Iverson et al. 2001, Bradshaw et al. 2003). Based on the premise that long-chain $\left(\mathrm{C}_{14}\right.$ or greater $)$ fatty acids are transferred from prey to predator tissues with understandable modification, the ratios of fatty acids within a predator's tissues are used to infer diet in accordance to the principle 'you are what you eat'. It has been suggested that because of the large complex array of fatty acids found within the marine environment they are ideal biomarkers for the study of trophic interactions within the oceans (Ackman 1980).

The use of fatty acids as indicators of diet has proven very successful at lower trophic levels. For example, Antarctic krill that were switched from a herbivorous to a carnivorous diet showed dramatic changes in their fatty acid composition (Cripps \& Atkinson 2000). At a higher trophic level, cod Gadus morhua that were switched from a diet of squid Ilex illecebrosus to mackerel Scomber scomberus increased their total lipid content, and their fatty acid composition changed to reflect that of their new diet (Kirsch et al. 1998).

Ethical and animal-size considerations has meant that fatty acid signature analysis involving top predators has relied on non-lethal sampling of accessible tissues such as blubber and milk. The use of fatty acids in milk as dietary indicators is complicated by the separation of feeding and suckling events in many marine mammals. In fasting animals, milk lipids are acquired from the mobilisation of fat reserves. In contrast, seals that intersperse periods ashore suckling their pups with periods feeding at sea are thought to have a milk fatty acid signature that reflects that of the prey consumed during their foraging trips (Iverson 1993). However, milk lipids have the potential to come from different sources (e.g. blubber, liver, blood), of which direct assimilation from the diet is only one. Even when the system is relatively simple and animals are fasting, Iverson et al. (1995) found that the fatty acid composition of a mother's milk was different compared to the make up of her adipose tissue. Despite the added complications in the use of milk fatty acid biomarkers in the study of higher trophic interactions, there has been very little testing of the technique and the underlying assumptions at this level. One such experiment did show a strong effect of dietary sources of fat on the fatty acid profile of mink milk Mustela vison after longterm intake (Wamberg et al. 1992). Two groups of Mink fed different diets for 3 mo prior to, and throughout, the lactation period had different ratios of polyunsaturated and monounsaturated fatty acids in their milk; these ratios reflected their dietary intake.
The waters around the sub-Antarctic island of South Georgia $\left(54^{\circ} \mathrm{S}, 38^{\circ} \mathrm{W}\right)$ are highly productive, and the food web is dominated by krill Euphausia superba (Atkinson et al. 2001). In terms of fish, the continental shelf is characterised by large concentrations of nototheniid species and mackerel icefish Champsocephalus gunnari, whereas myctophids proliferate in pelagic oceanic waters (Kock 1992, Kock \& Everson 1997). Modelling has highlighted the massive impact fur seals have on this ecosystem (Boyd 2002). It has been proposed that prey-switching by fur seals in periods of low krill abundance could cause the observed fluctuations in the region's commercially important stocks of mackerel icefish (Everson et al. 1999). In order to assess the role of these seals in this important and exploited ecosystem, it is essential to know their diet.

Female fur seals during the summer months have a fairly narrow dietary range dominated by krill and a few fish species (Reid \& Arnould 1996). At South Georgia female fur seals forage relatively close to the breeding beaches, and faecal material collected ashore is thought to be representative of prey taken on the foraging grounds (Staniland 2002). These factors, coupled with the relative ease in obtaining comparative faecal material from individuals, makes them an ideal subject with which to investigate the predictions of fatty acid signature analysis in higher trophic interactions. We used milk and faecal material from 8 individual female fur seals, concurrently collected throughout their breeding season, to address the following questions: (1) How variable is the milk fatty acid composition within a breeding season? (2) Can milk fatty acids be used to distinguish between foraging trips that show prey species differences in the corresponding enema? (3) Can distinctive groups of milk fatty acid signatures be related to characteristics of their preceding foraging trip?

\section{MATERIALS AND METHODS}

Collection and maintenance. We studied 8 female Antarctic fur seals Arctocephalus gazella from Freshwater Beach, Bird Island, South Georgia $\left(54^{\circ} 00^{\prime} \mathrm{S}, 38^{\circ} 02^{\prime} \mathrm{W}\right)$, throughout their breeding season in the austral summer of 1998/1999. These females were caught, using standard methods (Gentry \& Holt 1982), soon after they had given birth to their pups and a small $(6 \times 2 \times 2 \mathrm{~cm},<30 \mathrm{~g})$ radiotransmitter (Sirtrack) was glued to their fur in the mid-dorsal region (Boyd et al. 1998). The animals' subsequent attendance patterns were monitored using a scanning radio receiver (Televilt International $\mathrm{AB}, \mathrm{s}-71122)$. 
Seals were recaptured each time they returned from a foraging trip, and, when possible, milk and faecal material were collected. Samples were not collected until after the first foraging trip, so the perinatal period is not represented in this study. Milk collections were made using manual expression, aided by an intramuscular injection of $1 \mathrm{ml}$ oxytocin (InterVet). An antioxidant (1 $\mathrm{mg}$ butylated hydroxy toluene) was added to each $15 \mathrm{ml}$ sample that was then stored at $-20^{\circ} \mathrm{C}$ prior to analysis. Faecal material was collected concurrently by enema (Staniland et al. 2003) and processed according to the methods described in Reid (1995). Material was broken up in a $1 \%$ detergent solution by gentle agitation, so that prey remains were separated out. Material that was in suspension, e.g. krill carapaces, was poured into a sorting tray and examined. The dense residue remaining was examined under a binocular microscope, and prey remains such as fish otoliths, bones and eye lenses were picked out.

Enemas that contained no identifiable remains were labelled as 'unclassified'. Enemas that contained fish remains, as well as krill, were labelled by their family (i.e. nototheniid, myctophid, or icefish) if the otoliths could be identified, or simply as 'fish' if this was not possible. The incidence of fish in the diet of each individual was defined as the total number of its enemas containing fish remains divided by the total number of enemas. These were compared using a G-test of independence (Sokal \& Rohlf 1995). The median number of otoliths per enema was compared between individual seals using a Kruskal-Wallis test. To investigate seasonal patterns of fish consumption, the proportion of enemas containing fish remains was calculated for each week of the study and the total number of otoliths recovered was regressed against the week of collection. The 8 seals used in this study also formed part of a foraging experiment reported in Staniland et al. (2004).

Laboratory analysis. Milk samples were defrosted for $2 \mathrm{~h}$ at room temperature and homogenised using a whirlimixer. Total lipid was extracted as detailed by Folch et al. (1957), followed by trans-esterification in methanol containing $1.5 \%$ sulphuric acid at $50^{\circ} \mathrm{C}$ for $16 \mathrm{~h}$ to generate fatty acid methyl esters (FAME) (Christie 1982). FAME were purified by thin-layer chromatography (TLC) using a hexane:diethyl-ether: acetic acid (90:10:1, vol/vol/vol) solvent system. Purified FAME were extracted from the TLC in hexane: diethyl-ether (1:1 vol/vol). The solvent was evaporated under nitrogen, and the samples were dissolved in hexane to a concentration of $2 \mathrm{mg} \mathrm{ml}^{-1}$. FAME were analysed by capillary gas chromatography (GC) on a Hewlett-Packard 5890 fitted with a $25 \mathrm{~m} \times 0.25 \mathrm{~mm}$ i.d. column coated with $50 \%$ cyanopropyl polysiloxane
(0.2 $\mu \mathrm{m}$ film thickness, 52CB-Chrompack) using hydrogen as the carrier gas. FAME were identified by comparison to relative retention times from a standard mixture (Qualmix Fish Oil 89-5540). The major fatty acid constituents were labelled according to the shorthand notation: carbon chain length:number of double bonds and the location $(n-x)$ of the double bond nearest to the terminal methyl group.

Data analysis. Only fatty acids common to all samples were used in the data analysis, and, as they were expressed as a percentage mass of total fatty acids, the data were arcsine-transformed when used in parametric statistical analyses. Lipid mass was extracted, weighed and expressed as a percentage of the initial sample wet mass. A general linear model (GLM) was built in PROC GLM (SAS Institute) using these values as dependents and the date of collection and individual seal as independent variables. Using the model output, predicted values of percentage lipid mass were plotted against date of collection, taking into account differences between individual seals.

The main factors influencing the fatty acid profiles of the milk samples were investigated using principal components analysis to create a smaller number of indices representing the variation in the individual fatty acids. We used a co-variance matrix and set the number of components calculated to a level where additional components accounted for $<5 \%$ extra variation. The most influential fatty acids in each component were identified using the magnitude of their loadings to that component.

Milk samples were coded according to the identity of the seal (tag) from which they were collected, their date of collection (date) and the prey items found in the corresponding enema (enema). The effects of these 3 factors on the fatty acid signatures of the seal milk were then tested using a regression of the principal components. A GLM was built using the principal components as dependents and tag, date and enema as independent variables. Samples whose corresponding enema sample contained mixed fish or unidentified prey species were excluded from this analysis.

Canonical discriminant analysis (PROC DISCRIM, SAS Institute) was used to build a classification criterion with which to distinguish between samples grouped by the factors of tag and enema. All fatty acids were used to build canonical scores that are similar to principal components, except that they account for variance within and between the predesignated groupings of the data. Mahalanobis distances were calculated to test which groups were significantly different from each other. We used a smoothed error rate estimate to test the classification criterion. This was calculated using cross-validation by building the criterion using all but 1 of the observations and then using 
it to classify the remaining observation. This was repeated leaving out each observation in turn. The misclassification rate for each group was the proportion of samples from that group that were misclassified. The overall error rate was estimated through a weighted (by group size) average of the misclassification rate for each group. The classification criterion was further tested using the samples that concurrently had enemas with unidentified fish remains in them.

The important fatty acids in discriminating between the groups of tag and enema were identified using a stepwise discrimination method (PROC STEPDISC, SAS Institute). Fatty acids were chosen to enter or leave the model based on their contribution to the overall discriminatory power as measured by Wilk's Lambda, using a moderate significance level of 0.15 .

To examine which fatty acids changed over time, we calculated the Pearson's correlation coefficient between the continuous variable of date and each fatty acid. To compensate for multiple comparisons we used a Bonferroni correction $\left[1-(1-0.05)^{1 / 31}\right]$ of the $5 \%$ significance level.

The principal components analysis highlighted a number of samples that had fatty acid profiles that deviated appreciably from the main body of samples. To explore the factors causing these observed differences we grouped the samples by agglomerative clustering with complete linkage. We compared the mean collection date of samples between groups (where $\mathrm{n}>1$ ) using an ANOVA. Because of the small sample sizes, we could not test for differences between tag and enema.

To compare the geographical differences in the fatty acid signature of icefish, we compared an average sample of 3 specimens from South Georgia to 1 from the Kerguelen Plateau ( $\left.49^{\circ} 07^{\prime} \mathrm{S}, 70^{\circ} 45^{\prime} \mathrm{E}\right)$, as reported by Lea et al. (2002). A sample of krill taken from South Georgia was used as a reference. The fatty acids common to all 3 samples were used for comparison, and Euclidean distances were calculated using S-Plus 2000 (Mathsoft) agglomerative hierarchical clustering.

\section{RESULTS}

\section{Principal component analysis}

A summary of the major fatty acids of Antarctic fur seal Arctocephalus gazella milk used in the analysis is shown in Table 1. The first 4 principal components accounted for $>80 \%$ of the variation in milk fatty acids, and these were used in the subsequent GLM (Table 1). The loadings show which fatty acids had the most influence on each component; high absolute values indicate a strong influence (Table 1). Many of the fatty acids influential in the first 3 components were the same (i.e. 16:0, 18:1n-9, 20:1n-9 and 20:5n-3), although the direction (positive or negative) of this influence often differed. The fourth component was most strongly influenced by $16: 1 \mathrm{n}-7$ and 18:4n-3.

\section{Seasonal differences}

The GLM showed that the date on which a sample was collected had a significant effect on all 4 principal components, whereas enema and tag only had a significant effect on Component 2. Date and tag were significant in the overall model, but enema was not (Table 2). The 15 fatty acids that had a significant ( $\mathrm{p}<$ 0.0016, after Bonferroni correction) correlation with the date of collection are highlighted in Table 1. The changes over the season were gradual and approximately linear once individual variation had been accounted for (Fig. 1). The percentage lipid composition by mass of a milk sample was significantly related to both the date it was collected (multiple regression: $\left.\mathrm{r}^{2}{ }_{\text {adj }}=0.62, F_{1,122}=153.7, \mathrm{p}<0.001\right)$ and the individual seal from which it was taken $\left(F_{10,122}=4.99, \mathrm{p}<0.001\right)$. There were no distinct groups of individuals, but the lipid component of the seals' milk increased throughout the breeding season (Fig. 2).

\section{Dietary differences}

It was not possible to distinguish between milk samples based on the prey species found in the corresponding enema (canonical discrimination: Pillai's trace $=1.57, F_{93,66}=0.78, \mathrm{p}=0.863$ ). No groups were significantly different using Mahalanobis distances (maximum distance $=31.46, F_{31,20}=0.853, \mathrm{p}=0.663$ ), and cross-validation showed a high error rate $(0.11$, $\mathrm{p}=0.1$ ). Testing the classification criterion using samples in which unidentifiable fish remains were found in the enema showed that, although 8 were classified into 1 of the fish groups (myctophid, icefish, nototheniid), 7 were wrongly classified as pure krill samples.

\section{Individual differences}

Canonical discriminant analysis showed there were significant differences between individual seals (tag: canonical discrimination: Pillai's trace $=5.62, F_{217,154}=$ $2.89, \mathrm{p}<0.001)$. All but 2 tags were significantly different (w5342 and w5753, Mahalanobis distance = 10.91, $F_{31,51}=1.27, \mathrm{p}=0.219$ ). The least similar individuals were w5585 and w2363 (distance $=93.83, F_{31,51}=$ 


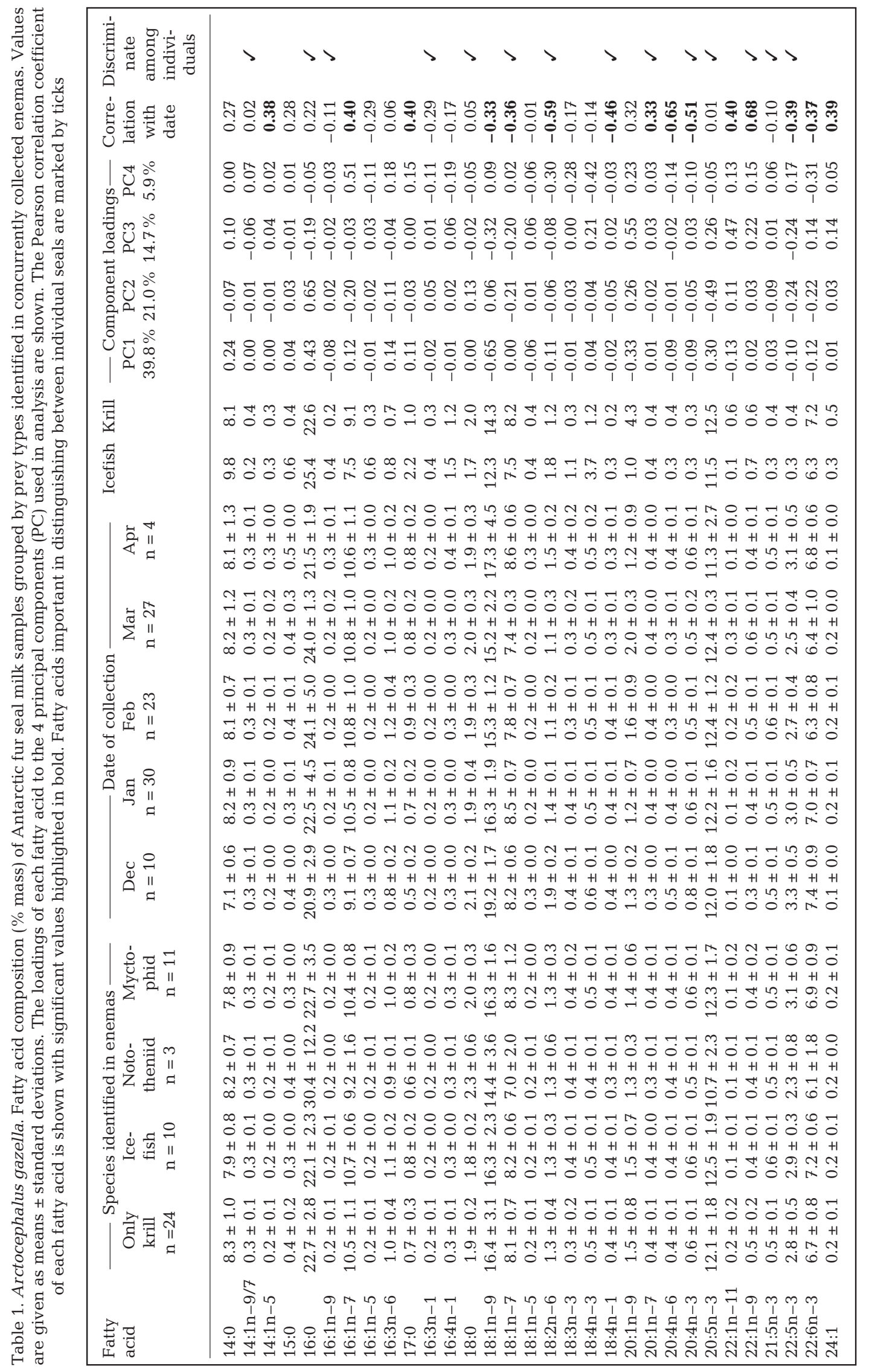


Table 2. Arctocephalus gazella. A general linear model testing the influence of date of collection (Date), individual seal (Tag) and prey identified in faecal material (Enema) on 4 principal components (PC) representing the fatty acid composition of Antarctic fur seal milk. Significant factors are highlighted in bold for each component and the overall model

\begin{tabular}{|c|c|c|c|c|c|c|c|c|c|c|c|c|}
\hline \multirow[t]{3}{*}{ Factor } & \multirow[t]{3}{*}{ df } & \multicolumn{8}{|c|}{ - Principal component } & \multirow{2}{*}{\multicolumn{3}{|c|}{$\begin{array}{c}\text { Overall model } \\
\text { MANOVA (Pillai's trace) }\end{array}$}} \\
\hline & & \multicolumn{2}{|c|}{ PC1 } & \multicolumn{2}{|c|}{$\mathrm{PC} 2$} & \multicolumn{2}{|c|}{ PC3 } & \multicolumn{2}{|c|}{ PC4 } & & & \\
\hline & & $F$ & $\mathrm{p}$ & $F$ & $\mathrm{p}$ & $F$ & $\mathrm{p}$ & $F$ & $\mathrm{p}$ & $\mathrm{df}$ & $F$ & $\mathrm{p}$ \\
\hline Tag & 7 & 0.86 & 0.542 & 3.54 & 0.005 & 2.07 & 0.068 & 1.73 & 0.114 & 28/168 & 1.84 & 0.010 \\
\hline Date & 1 & 7.85 & 0.008 & 9.64 & 0.003 & 20.53 & $<0.001$ & 34.59 & $<0.001$ & 1/39 & 16.77 & $<0.001$ \\
\hline Enema & 3 & 0.77 & 0.516 & 5.64 & 0.002 & 0.61 & 0.609 & 1.1 & 0.358 & $12 / 123$ & 1.43 & 0.163 \\
\hline
\end{tabular}

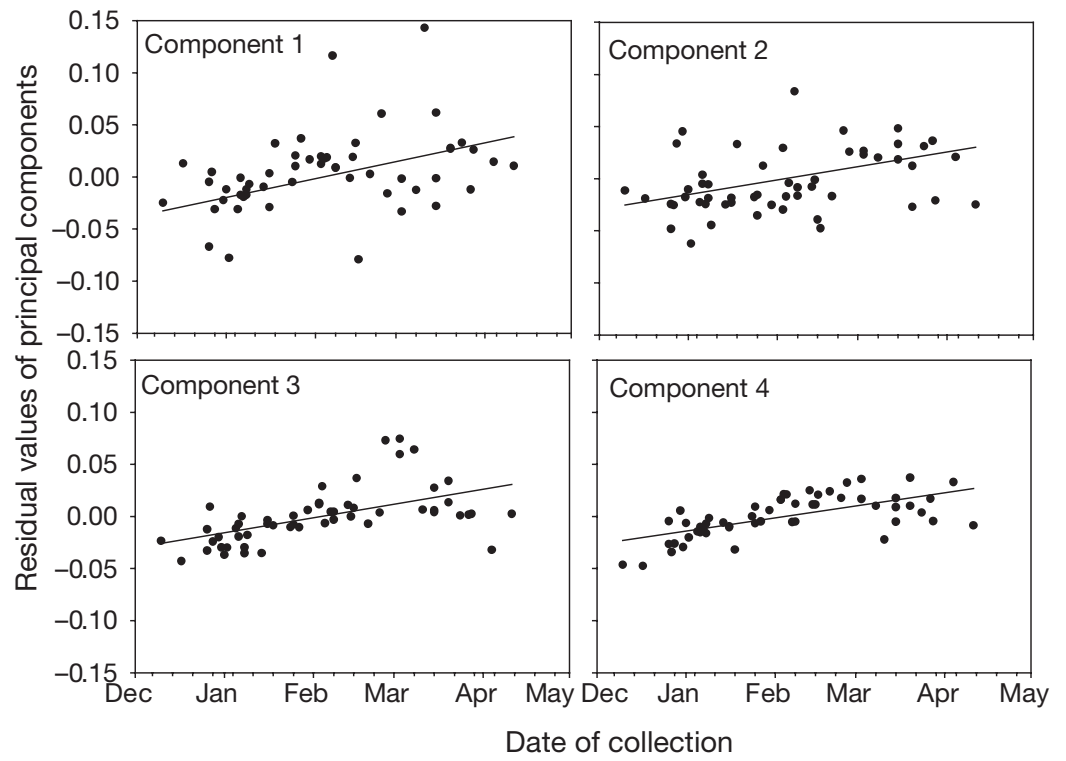

Fig. 1. Arctocephalus gazella. Changes in the fatty acid profiles of Antarctic fur seal milk over the course of the breeding season after taking into account individual variation. The resulting residual values are shown for each of the 4 main principal components that were used to represent the fatty acid composition of the seal milk in its enemas (Table 3), but when this seal was removed from the analysis there was no significant difference between the other individuals. A total of $46 \%$ of the enemas showed evidence of fish consumption, and myctophids were the most common group identified. Of the 3 seals with the highest number of otoliths in their enemas, w5585 had a diet dominated by nototheniids and icefish, whereas myctophids dominated the diet of w2317 and w5342.

There was no evidence of an increase in fish consumption throughout the breeding season; the proportion of enemas containing fish remains did not increase (Fig. 3), and there was no pattern in the number of otoliths occurring in each week (regression: $r^{2}=0.04$, $\left.F_{1,20}=1.84, \mathrm{p}=0.191\right)$.

\section{Clustering analysis}

12.09, $\mathrm{p}<0.001)$. The discriminant function performed well with cross-validation, and all but 3 samples were correctly assigned to the individual seal from which they were taken (error rate $=0.045, p=0.031$ ). The 14 fatty acids important in discriminating between individual seals are shown in Table 1. Four of these (16:0, 18:1n-7, 20:5n-3 and 22:5n-3) were also big influences on the second principal component.

\section{Enemas}

The incidence of fish was not significantly different between seals ( $G$-test of independence: $G_{\mathrm{adj}}=9.288$, $\mathrm{df}=8, \mathrm{p}=0.454)$. However, comparing the median number of otoliths per sample showed significant differences (Kruskal-Wallis test: $H=16.39$, df $=7, \mathrm{p}=$ 0.022 ). w5585 had a much greater number of otoliths
Clustering the samples provided 4 groups using a dissimilarity index with a cut-off value of 0.2 . We chose this value as our aim was to identify major groupings. Increasing the number of clusters simply led to more groups containing low numbers of samples, e.g. a cut-off value of 0.15 created 7 clusters of which 3 had 2 or less members. Over $76 \%$ of the samples were contained within Cluster 1. The smallest cluster (3) contained only 1 sample and was not used in the subsequent analysis (Table 4). There were significant differences between the mean date of collection of the clusters (GLM: date $=$ cluster: $F_{2,90}=4.70$, $\mathrm{p}=0.011$ ), as, on average, samples in Cluster 2 were collected later in the year than those in Cluster 1 (Tukey simultaneous tests: $t=3.016, \mathrm{p}_{\mathrm{adj}}=0.011$ ). Although we could not test for specific patterns, no groupings were entirely made up of 1 prey type or an individual seal. 


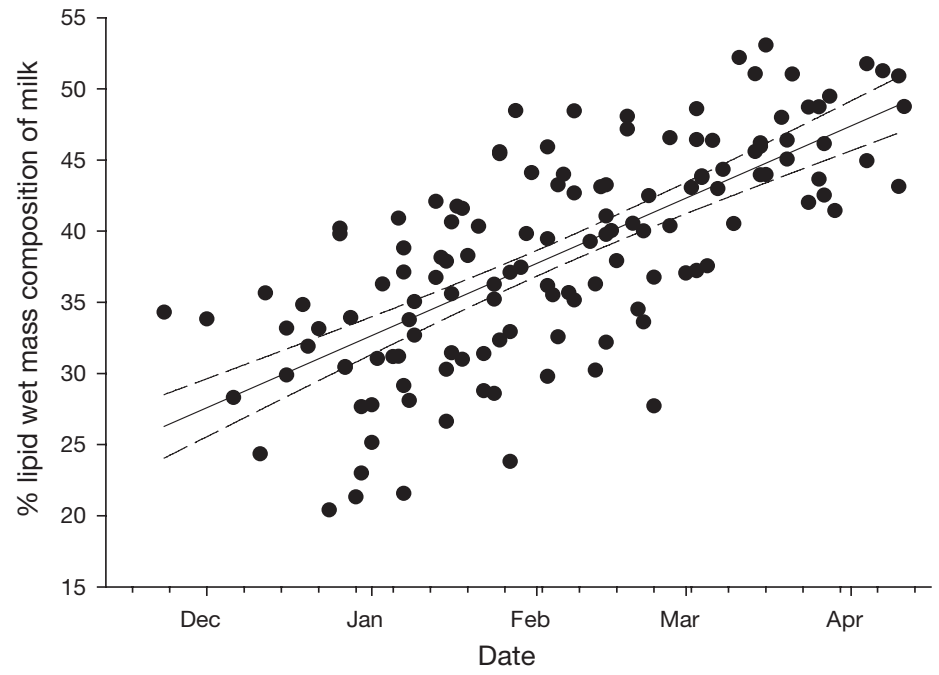

Fig. 2. Arctocephalus gazella. Changes in the predicted values of percentage wet mass of the lipid component in Antarctic fur seal milk samples throughout the breeding season after taking into account individual variation. The fitted linear regression $(\%$ lipid $=$ day $\times 0.164+26.27)$ is shown with $95 \%$ confidence limits

\section{Prey species}

The comparison of the prey species showed that icefish from South Georgia (S.G.) were more similar to krill in their fatty acid composition than they were to the icefish from the Kerguelen Plateau (K.P.) (Euclidean distance from S.G. icefish: krill = 6.58, K.P. icefish = 8.64).

\section{DISCUSSION}

In this study the composition of milk fatty acids in Antarctic fur seals Arctocephalus gazella was most strongly linked to the date of collection, with evidence of differences among individual seals. Milk samples grouped by similar diets (as suggested by their corresponding enema samples) could not be successfully distinguished by their fatty acid signatures. In addition, groups of samples with similar fatty acid profiles did not show any association with the dietary evidence in the enemas, but they had some association with the date of collection.

\section{Seasonal differences}

Principal components analysis could account for $>80 \%$ the variation observed in the fatty acid composition of the milk samples using only 4 components. Of the fatty acids with a major influence (loading) in these components 20:5n-3 and 18:4n-3 are thought to be entirely derived from diet (Iverson 1993). Changes over the season appeared to be gradual, with no obvious steps or peaks in the distribution of the principal components over time (Fig. 1). Therefore, either the factors affecting the milk fatty acid profiles were themselves subject to gradual change and/or any changes were buffered by the physiology of milk production within the animals.

There was a strong seasonal influence on the fatty acid composition of milk, with date of collection significantly related to the 4 principal components. Individually 15 of the fatty acids were significantly correlated to the date of collection, although some caution should be attached to this result as the percentage values were not independent. There was also a strong seasonal influence in the amount of lipid in a milk sample, shown by a significant positive relationship with the date of collection. The increase in the overall lipid content of milk samples means that the fatty

Table 3. Arctocephalus gazella. Individual female Antarctic fur seals serially sampled during the 1998/1999 breeding season. The number of captures made, the number of samples taken, the total number of otoliths of each fish group, and the number of enemas they were found in $(f)$ are all shown for each individual seal used in the study. The overall total of otoliths also contains ones that were too eroded for identification

\begin{tabular}{|c|c|c|c|c|c|c|c|c|c|c|c|c|c|c|c|}
\hline $\begin{array}{l}\text { Seal ID } \\
\text { (tag) }\end{array}$ & $\begin{array}{c}\text { Mass } \\
(\mathrm{kg})\end{array}$ & $\begin{array}{l}\text { Length } \\
\text { (cm) }\end{array}$ & $\begin{array}{c}\text { Age } \\
\text { (yr) } \\
\end{array}$ & $\begin{array}{l}\text { Age of } \\
\text { pup at } \\
\text { first milk } \\
\text { ample (d) }\end{array}$ & $\begin{array}{l}\text { No. of } \\
\text { captures }\end{array}$ & $\begin{array}{c}\text { No. of } \\
\text { milk } \\
\text { samples }\end{array}$ & $\begin{array}{l}\text { No. of } \\
\text { enemas }\end{array}$ & $\begin{array}{l}\text { No. } \\
\text { with } \\
\text { fish }\end{array}$ & $\begin{array}{c}\text { Total } \\
\text { otoliths }\end{array}$ & $\begin{array}{l}\text { Noto } \\
f\end{array}$ & $\begin{array}{l}\text { theniids } \\
\text { Otoliths }\end{array}$ & $f$ & $\begin{array}{l}\text { cefish } \\
\text { Otoliths }\end{array}$ & & $\begin{array}{l}\text { ctophids } \\
\text { Otoliths }\end{array}$ \\
\hline w1753 & 45.0 & 134 & 20 & 19 & 12 & 11 & 11 & 4 & 4 & 1 & 2 & 1 & 2 & & \\
\hline w2317 & 44.5 & 130 & 14 & 17 & 9 & 8 & 9 & 6 & 11 & & & 1 & 2 & 4 & 7 \\
\hline w2363 & 46.0 & 131 & 8 & 23 & 15 & 15 & 13 & 5 & 4 & & & 1 & 1 & 2 & 3 \\
\hline w5341 & 39.5 & 140 & 10 & 16 & 12 & 11 & 12 & 3 & 3 & & & 1 & 1 & 1 & 1 \\
\hline w5342 & 32.0 & 121 & 9 & 23 & 12 & 12 & 12 & 4 & 18 & & & 1 & 1 & 1 & 14 \\
\hline w5511 & 44.0 & 142 & 10 & 13 & 14 & 10 & 13 & 7 & 4 & & & 1 & 1 & 1 & 1 \\
\hline w5585 & 40.0 & 132 & 9 & 12 & 14 & 14 & 14 & 8 & 64 & 2 & 20 & 5 & 15 & 1 & 1 \\
\hline w5753 & 38.0 & 138 & Unknown & 12 & 12 & 11 & 12 & 7 & 3 & 1 & 1 & 2 & 3 & & \\
\hline Total & & & & & 100 & 92 & 96 & 44 & 111 & 4 & 23 & 13 & 26 & 10 & 27 \\
\hline
\end{tabular}




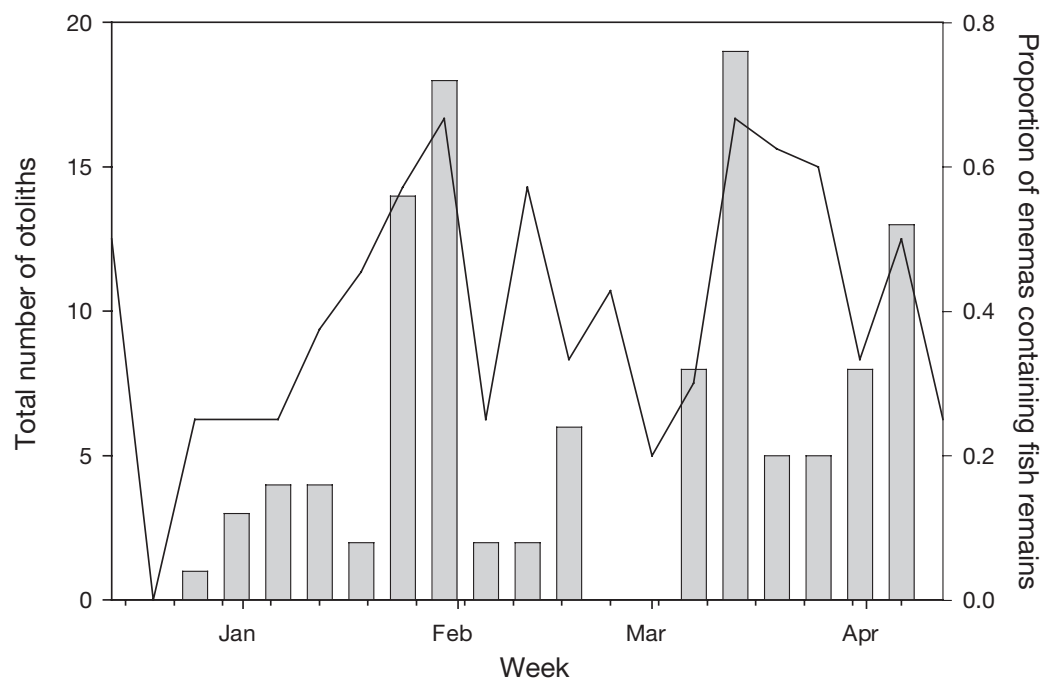

Fig. 3. Arctocephalus gazella. Total number of otoliths recovered from enemas each week during the Antarctic fur seal breeding season, represented by solid bars. The proportion of enemas that contained fish remains for each week are shown by the black line

acids that decreased in percentage mass composition over the season may simply have remained at a constant level in the overall milk. Fatty acids with a constant percentage contribution over the season would actually have increased. Of the 15 fatty acids that had a strong correlation with date of collection, 8 are thought to be mostly derived from diet. These included the 5 strongest relationships (correlation coefficient $>0.45$ ).

\section{Comparison with faecal sampling predictions}

Iverson et al. (1997) also found seasonal differences in the fatty acid composition of Antarctic fur seal milk using samples collected in December, early February and mid-March. They suggested that the increase of 20:1n-9 and 22:1n-11, and the associated decrease in 14:0 and 20:5n-3 levels, was due to an increased consumption of fish in the latter part of the breeding season, which was observed in scats collected from around the breeding beaches. However, Brown et al. (1999) were unable to associate milk samples collected from the same population in March of the same year with any fish prey species examined. If the seasonal differences in the current study were caused by increased consumption of fish, then we would have expected 2 things, firstly, that the amount of fish occurring in enemas would increase during the breeding season and, secondly, that milk samples from trips that showed fish predation would have different signatures from those that simply contained krill. However, there was no consistent change in the number of otoliths found, or in the proportion of enemas containing fish remains over time. We were unable to distinguish between fatty acid profiles of samples grouped by the appearance of different prey species in their enemas. The discriminant function performed very poorly with a high cross-validation error rate that is indicative of indistinct overlapping groups. Nearly half of the milk samples with concurrent enemas containing unidentified fish were incorrectly assigned as containing only krill when the criterion was tested. In the GLM, whilst season showed a strong relationship with all the major components, enema was only related to the second principal component and was not significant in the overall model.

It could be argued that the biases associated in faecal sampling are so great that they are masking the true patterns of fish consumption. It is undoubtedly true that in some cases when fish were consumed during a foraging trip there may have been no remains in the resulting enema, but we would not expect enemas that contained fish remains to be classified as trips during which only krill were consumed. As fish have many parts resistant to digestion (otoliths, eye lenses and bones), it is known that they will be represented in $>1$ scat (Tollit et al. 2003). Therefore, faecal material collected from an individual ashore will not simply represent the last meal; indeed, fish consumption can be detected via hard parts up to and over $4 \mathrm{~d}$ after ingestion (Staniland 2002, Tollit et al. 2003). Captive feeding trials have suggested that, at Bird Island, faecal material collected ashore would be representative of the main foraging areas in all but the very longest trips (Staniland 2002). In addition, the fact that myctophids, concentrated in the more distant oceanic waters, were the most common fish prey suggests that there was no systematic bias in the faecal collections.

Whilst we cannot use faecal material as a strict control in this study, we do know that the potential biases involved have not masked seasonal trends, such as increasing fish consumption, in previous seasons. A 4 yr study using faecal analysis at the same colony showed an increase in myctophid prey in the later months of the breeding season during 3 of those years (Reid \& Arnould 1996). This myctophid pulse during February and March is common, but does not occur every season and was not observed in the year of this study. 
Table 4. Arctocephalus gazella. Summary of the 4 groups suggested by agglomerative cluster analysis with a cut-off value of 0.2 . Values represent the number of samples in each cluster and the total number of samples from each individual seal, the diet derived from enemas and the month of collection. Mean dates of collection that were significantly different between clusters are highlighted in bold

\begin{tabular}{|c|c|c|c|c|c|c|c|c|c|c|c|c|c|c|c|c|c|c|c|c|c|c|}
\hline \multirow[t]{2}{*}{ Cluster } & \multirow[t]{2}{*}{$\mathrm{n}$} & \multicolumn{8}{|c|}{$\longrightarrow$ Individual seals } & \multicolumn{6}{|c|}{$\longrightarrow$ Prey remains in enema -} & \multicolumn{7}{|c|}{$\longrightarrow$ Month of collection -} \\
\hline & & s & $\stackrel{3}{3}$ & ई & 3 & $5^{2}$ & डे & 3 & ŝ & $\begin{array}{l}\text { Krill } \\
\text { only }\end{array}$ & $\begin{array}{l}\text { Ice- } \\
\text { fish }\end{array}$ & $\begin{array}{l}\text { Noto- } \\
\text { theniid }\end{array}$ & $\begin{array}{l}\text { Mycto- } \\
\text { phid }\end{array}$ & $\begin{array}{l}\text { Unident. } \\
\text { fish }\end{array}$ & $\begin{array}{l}\text { Mixed } \\
\text { prey }\end{array}$ & Dec & Jan & Feb & Mar & Apr & $\begin{array}{l}\text { Mean } \\
\text { date }\end{array}$ & $\begin{array}{l}\text { SEM } \\
\text { (d) }\end{array}$ \\
\hline 1 & 68 & 6 & 6 & 11 & 8 & 11 & 9 & 6 & 11 & 24 & 9 & 2 & 9 & 13 & 1 & 9 & 28 & 16 & 15 & 4 & 4 Feb & 4 \\
\hline 2 & 14 & 4 & 2 & 3 & 1 & 1 & 1 & 2 & 0 & 8 & 1 & 0 & 2 & 1 & 1 & 0 & 1 & 3 & 11 & 0 & 4 Mar & 5 \\
\hline 3 & 1 & 0 & 0 & 0 & 1 & 0 & 0 & 0 & 0 & 1 & 0 & 0 & 0 & 0 & 0 & 1 & 0 & 0 & 0 & 0 & & \\
\hline 4 & 6 & 1 & 0 & 1 & 1 & 0 & 0 & 3 & 0 & 2 & 0 & 1 & 0 & 1 & 1 & 0 & 1 & 4 & 1 & 0 & 16 Feb & 6 \\
\hline Total & 89 & 11 & 8 & 15 & 11 & 12 & 10 & 11 & 11 & 35 & 10 & 3 & 11 & 15 & 3 & 10 & 30 & 23 & 27 & 4 & & \\
\hline
\end{tabular}

\section{Clustering samples by similarities in their fatty acid signatures}

The results of clustering milk samples based on similarities in their fatty acid signatures showed some association with the date of collection, but not with the dietary information from enemas. The dietary groupings derived from enema data were distributed evenly throughout the clusters, and no cluster, with $>1$ member, was made up of 1 type of prey. Even allowing for biases in the enema data, we would expect that if diet was having a strong influence on the milk samples that these clusters would separate the majority of dietary types or at least the occasions on which different fish species were eaten, e.g. myctophids and icefish. However, this is clearly not the case.

An additional problem with the interpretation of Iverson et al. (1997) is that the seasonal increases in 22:1n-11 and 20:1n-9 were not associated with an increase in the variability of these values, i.e. all late season milk samples showed elevated levels. This would suggest that all the seals in their study were changing their diet in the same way and at the same time. Recent work has shown that there are strong individual differences in the foraging behaviour of the Antarctic fur seal population (Staniland et al. 2004). Therefore, it would seem highly unlikely that all individuals changed their diet around the same time in the season. If changes in the diet were the cause in seasonal variability, then we would expect the variability in the population's milk composition to increase as some animals ate more fish and others did not.

Iverson et al. (1997) linked the seasonal changes in milk fatty acids they observed to a parallel pattern of increased fish consumption towards the end of the breeding season. However, despite a lack of evidence of increasing fish consumption within our year of study, we still found similar seasonal patterns in the milk fatty acid profiles. The consistency between the results of Iverson et al. (1997) and the present study suggests that other factors are causing these seasonal changes. If increased fish consumption is unlikely, the question remains: What causes the seasonal patterns observed within the composition of fur seal milk? One explanation could still lie in the dietary intake of the seals. Krill is the main prey of these animals during the summer months (Reid \& Arnould 1996), and it is the central component of the food web in the South Georgia area. The fatty acid signature of krill changes in relation to its diet, with significant increases in both 20:5n-3 and 22:6n-3 when fed copepods (Cripps \& Atkinson 2000). There is an increase in the total lipid content of krill throughout the Antarctic summer months, with a build-up of triglycerols (Falk-Petersen et al. 2000), and there is evidence that the fatty acid composition of krill changes throughout the season, although patterns were not consistent between studies (Shibata 1983, Falk-Petersen et al. 2000).

The seasonal changes in fur seal milk may be the influence of changes in diet further down the trophic chain. The increase in fatty acids such as 20:5n-3 and 18:4n-3, which are indicative of diatoms and copepods, could be a result of a dietary shift in the krill that is then reflected in the milk of fur seals which eat them. Other researchers have suggested that within-species variability is less than between-species differences, but even in these studies differences between age classes have to be taken into account (Iverson et al. 2002). In addition, these have not addressed the situation of rapidly growing omnivorous zooplankton, such as krill, that can show large differences between areas $<20 \mathrm{~km}$ apart (Cripps et al. 1999). In the summer months around South Georgia, krill are thought to moult between 15 and $30 \mathrm{~d}$. Subsequently, the effects of dietary changes on the fatty acid composition of their bodies can be very rapid and large, with a reported doubling of the PUFA (polyunsaturated fatty acid) concentration within $16 \mathrm{~d}$ of a diet switch (Cripps \& Atkinson 2000). 
In addition to the potential complication of variations in the krill fatty acid signature, there are also uncertainties with regard to fish prey. South Georgia icefish had a more similar fatty acid signature to krill than to conspecifics caught on the Kerguelen Plateau. Although the sample sizes were small, the difference among icefish from different parts of the geographical range is not surprising, and these differences highlight a potential problem. The differences are most likely due to disparity in the icefish diet in the 2 regions. Krill are the major component in the icefish diet at South Georgia (Kock et al. 1994), whereas icefish in Kerguelen waters consume Euphausia vallenti and Thermisto gaudichaudii (Lea et al. 2002). It is also likely that the other fish species consumed by fur seals are predating on krill and that this could cause identification problems. The fatty acid signatures of cod have been shown to change to resemble their prey (Kirsch et al. 1998), and Iverson et al. (2002) showed that fish species that ate the same prey had the highest probability of being misclassified when they were grouped according to their fatty acid signatures. The similarity of the prey species' signatures may be one of the reasons for the lack of association between the occurrence of fish in enemas and the fatty acid composition of the milk samples. Given that the fur seals at South Georgia are thought to consume mostly krill, with an opportunistic supplementation with fish, then the relatively small consumption of fish species may be masked by other factors. It is important to note, however, that given the large numbers of seals around South Georgia, even with minor fish predation on an individual level, the impact of the population on commercially important fish species is potentially massive.

An alternative or complimentary hypothesis could lie in the demands of the pup. Milk production in seals is thought to be independent of their environment, as they can increase the fat content of their milk even when fasting (Iverson 1993). The lipid content of the fur seals' milk in this study steadily increased throughout the season, probably in response to the increasing energetic demands and the development of the pups. The change in fatty acid composition of the milk may have been a reflection of this increase, as the mothers selectively mobilised certain fatty acids their pups required at different stages of their development. Such selective mobilisation has been seen in fasting phocids, over short lactation periods, with differences between maternal blubber and milk. Grahl-Nielsen et al. (2000) found systematic changes in grey seal Halichoerus grypus milk, with elevated levels of the fatty acids that appeared to be metabolised by pups more readily, e.g. 22:6n-3, 20:5n-3, 18:0 and monounsaturated 20 carbon atoms. However, their study was based on small samples of blubber and must be regarded with caution.
Iverson et al. (1995) also showed elevated levels of 20:5n-3, as well as other minor fatty acid composition changes, throughout the 4-d lactation period of hooded seals Cystophora cristata. The fatty acid composition of human milk varies with the duration of lactation. The contents of essential fatty acids $18: 2 n-6$ and 18:3n-3 increase with milk maturation, whereas the percentages of long-chain PUFAs in the n- 6 and n-3 series decrease markedly (by $50 \%$ in some cases) (Koletzko et al. 2001). Milk samples were not collected during the perinatal period, because the extended fasting (around $10 \mathrm{~d}$ ) at this time would mean that the mothers were relying on the mobilisation of fat reserves built up during winter foraging. This period was outside the scope of this experiment. However, the differential mobilisation of fat reserves throughout the season may be another possible explanation for the observed temporal changes in the composition of the milk.

\section{Individual differences}

In the current study, we followed the same individual seals throughout their lactation and could investigate individual variation in milk fatty acid composition. There were differences between individuals, and, although this was not as strong a factor as date of collection, tag was significant in the overall model. The discriminant analysis showed that all but 2 seals could be distinguished using their fatty acid signatures. Staniland \& Pond (2004) showed significant differences between milk fatty acids of individual seals fed the same diet and, because the retention times of fatty acids in the mammary are unknown, suggested there may have been an influence of feeding prior to the experiment. If this were the case, then, according to the assumptions of signature analysis, we should have been able to detect differences in the milk fatty acids of individual seals that displayed differences in their diets over the season. The prey remains in the enemas did not support this; whilst there were differences, those seals with the largest differences in milk composition (w5585 and w2363) were not the most different in terms of their enemas. In addition, seals with similar fish prey in their enemas had significantly different signatures, e.g. w2363, w5341 and w5753.

\section{CONCLUSIONS}

The major finding in this study was the complete lack of correlation between the predictions of faecal sampling and the use of milk fatty acids as dietary markers. The potential biases of faecal sampling may have complicated comparisons at the individual trip 
level. However, we would not expect this to have affected comparisons of seasonal trends. Although it is clear that diet does have an influence on the fatty acid composition of a predator at lower trophic levels, the picture becomes more complicated higher up the food chain. The use of specific tissues/products, such as milk, means that to interpret results not only is a detailed knowledge of the physiology of the predator needed, but also a thorough understanding of its potential prey, their fatty acid signatures and the variability of those signatures. The production of milk and the factors influencing its composition appear to be complex, especially in those seal species which forage throughout lactation. We conclude that comprehensive testing is required, through feeding and field trials, before the full potential of milk fatty acid signature analysis can be realised.

Acknowledgements. We thank all the staff at the Bird Island Research Station, in particular R. Taylor, for their help in fieldwork. K. Snell helped prepare the lipid samples, and C. Reid of Mylnefield Research Services Ltd processed them. K. Reid, T. Martin and 5 referees provided useful comments on earlier drafts of this manuscript.

\section{LITERATURE CITED}

Ackman RG (1980) Fish lipids. Part 1. In: Connell JJ (ed) Advances in fish science and technology. Fishing News Books, Surrey, p 86-103

Atkinson A, Whitehouse MJ, Priddle J, Cripps GC, Ward P, Brandon MA (2001) South Georgia, Antarctica: a productive, cold water, pelagic ecosystem. Mar Ecol Prog Ser 216: 279-308

Boyd IL (2002) Estimating food consumption of marine predators: Antarctic fur seals and macaroni penguins. J Appl Ecol 39:103-119

Boyd IL, Murray AWA (2001) Monitoring a marine ecosystem using responses of upper trophic level predators. J Anim Ecol 70:747-760

Boyd IL, McCafferty DJ, Reid K, Taylor R, Walker TR (1998) Dispersal of male and female Antarctic fur seals Arctocephalus gazella. Can Fish Aquat Sci 55:845-852

Bradshaw CJA, Hindell MA, Best NJ, Phillips KL, Wilson G, Nichols PD (2003) You are what you eat: describing the foraging ecology of southern elephant seals (Mirounga leonina) using blubber fatty acids. Proc R Soc Lond B 270: 1283-1292

Brown DJ, Boyd IL, Cripps GC, Butler PJ (1999) Fatty acid signature analysis from the milk of Antarctic fur seals and southern elephant seals from South Georgia: implications for diet determination. Mar Ecol Prog Ser 187:251-263

Cherel Y, Weimerskirch H (1995) Seabirds as indicators of marine resources: black-browed albatrosses feeding on ommastrephid squids in Kerguelen waters. Mar Ecol Prog Ser 129:295-300

Christie WW (1982) Lipid analysis. Pergamon Press, Oxford

Cripps GC, Atkinson A (2000) Fatty acid composition as an indicator of carnivory in Antarctic krill, Euphausia superba. Can J Fish Aquat Sci 57:31-37

Cripps GC, Watkins JL, Hill HJ, Atkinson A (1999) Fatty acid content of Antarctic krill Euphausia superba at South
Georgia related to regional populations and variations in diet. Mar Ecol Prog Ser 181:177-188

Everson I, Parkes G, Kock KH, Boyd IL (1999) Variation in standing stock of the mackerel icefish Champsocephalus gunnari at South Georgia. J Appl Ecol 36:591-603

Falk-Petersen S, Hagen W, Kattner G, Clarke A, Sargent J (2000) Lipids, trophic relationships, and biodiversity in Arctic and Antarctic krill. Can J Fish Aquat Sci 57:178-191

Folch J, Lees N, Sloan-Stanley GH (1957) A simple method for the isolation and purification of total lipid. J Biol Chem 226:497-509

Gentry RL, Holt JR (1982) Equipment and techniques for handling northern fur seals. Report No. NMFS SSRF 758. US Department of Commerce, NOAA, Seattle, WA

Graeve M, Kattner G, Wiencke C, Karsten U (2002) Fatty acid composition of Arctic and Antarctic macroalgae: indicator of phylogenetic and trophic relationships. Mar Ecol Prog Ser 231:67-74

Grahl-Nielsen O, Hammill MO, Lydersen C, Wahlstrom S (2000) Transfer of fatty acids from female seal blubber via milk to pup blubber. J Comp Physiol B Biochem Syst Environ Physiol 170:277-283

Gremillet D, Wilson RP, Wanless S, Chater T (2000) Blackbrowed albatrosses, international fisheries and the Patagonian Shelf. Mar Ecol Prog Ser 195:269-280

Harvey JT (1989) Assessment of errors associated with harbor seal (Phoca vitulina) faecal sampling. J Zool 219:101-111

Helm RC (1984) Rate of digestion in 3 species of pinnipeds. Can J Zool 62:1751-1756

Hooker SK, Iverson SJ, Ostrom P, Smith SC (2001) Diet of northern bottlenose whales inferred from fatty-acid and stable-isotope analyses of biopsy samples. Can J Zool 79: $1442-1454$

Iverson SJ (1993) Milk secretion in marine mammals in relation to foraging: can milk fatty acids predict diet? Symp Zool Soc Lond 66:263-291

Iverson SJ, Oftedal OT, Bowen WD, Boness DJ, Sampugna J (1995) Prenatal and postnatal transfer of fatty-acids from mother to pup in the hooded seal. J Comp Physiol B 165: $1-12$

Iverson SJ, Arnould JPY, Boyd IL (1997) Milk fatty acid signatures indicate both major and minor shifts in the diet of lactating Antarctic fur seals. Can J Zool 75:188-197

Iverson SJ, McDonald JE, Smith LK (2001) Changes in the diet of free-ranging black bears in years of contrasting food availability revealed through milk fatty acids. Can J Zool 79:2268-2279

Iverson SJ, Frost KJ, Lang SLC (2002) Fat content and fatty acid composition of forage fish and invertebrates in Prince William Sound, Alaska: factors contributing to among and within species variability. Mar Ecol Prog Ser 241:161-181

Kirsch PE, Iverson SJ, Bowen WD, Kerr SR, Ackman RG (1998) Dietary effects on the fatty acid signature of whole Atlantic cod (Gadus morhua). Can J Fish Aquat Sci 55: 1378-1386

Kock KH (1992) Antarctic fish and fisheries. Cambridge University Press, Cambridge

Kock KH, Everson I (1997) Biology and ecology of mackerel icefish, Champsocephalus gunnari: an Antarctic fish lacking hemoglobin. Comp Biochem Physiol A 118:1067-1077

Kock KH, Wilhelms S, Everson I, Groger J (1994) Variations in the diet composition and feeding intensity of mackerel icefish Champsocephalus gunnari at South Georgia (Antarctic). Mar Ecol Prog Ser 108:43-57

Koletzko B, Rodriguez-Palmero M, Demmelmair H, Fidler N, Jensen R, Sauerwald T (2001) Physiological aspects of human milk lipids. Early Hum Dev 65(Suppl):3-18 
Lea MA, Nichols PD, Wilson G (2002) Fatty acid composition of lipid-rich myctophids and mackerel icefish (Champsocephalus gunnari) - Southern Ocean food-web implications. Polar Biol 25:843-854

McConnell BJ, Fedak MA, Lovell P, Hammond PS (1999) Movements and foraging areas of grey seals in the North Sea. J Appl Ecol 36:573-590

Pierce GJ, Boyle PR (1991) A review of methods for diet analysis in piscivorous marine mammals. Oceanogr Mar Biol Annu Rev 29:409-486

Raclot T, Groscolas R, Cherel Y (1998) Fatty acid evidence for the importance of myctophid fishes in the diet of king penguins, Aptenodytes patagonicus. Mar Biol 132: 523-533

Reid K (1995) The diet of Antarctic fur seals Arctocephalus gazella Peters, 1875 during winter at South Georgia. Antarct Sci 7(3):241-249

Reid K, Arnould JPY (1996) The diet of Antarctic fur seals Arctocephalus gazella during the breeding season at South Georgia. Polar Biol 16:105-114

Reuss N, Poulsen LK (2002) Evaluation of fatty acids as biomarkers for a natural plankton community: a field study of a spring bloom and a post-bloom period off West Greenland. Mar Biol 141:423-434

Rindorf A, Wanless S, Harris MP (2000) Effects of changes in sandeel availability on the reproductive output of seabirds. Mar Ecol Prog Ser 202:241-252

Rodhouse PG, Prince PA, Trathan PN, Hatfield EMC, Watkins JL, Bone DG, Murphy EJ, White MG (1996) Cephalopods and mesoscale oceanography at the Antarctic Polar Front: satellite tracked predators locate pelagic trophic interactions. Mar Ecol Prog Ser 136:37-50

Shibata N (1983) Effect of fishing season on lipid-content and

Editorial responsibility: Otto Kinne (Editor-in-Chief), Oldendorf/Luhe, Germany composition of Antarctic krill. Bull Jpn Soc Fish Oceanogr 49:259-264

Sokal RR, Rohlf FJ (1995) Biometry. WH Freeman, San Francisco, CA

Staniland IJ (2002) Investigating the biases in the use of hard prey remains to identify diet composition using Antarctic fur seals (Arctocephalus gazella) in captive feeding trials. Mar Mamm Sci 18:223-243

Staniland IJ, Pond D (2004) Variability in milk fatty acids: recreating a foraging trip to test dietary predictions in Antarctic fur seals. Can J Zool 82:1099-1107

Staniland IJ, Taylor RI, Boyd IL (2003) An enema method for obtaining faecal material from known individual seals on land. Mar Mamm Sci 19:363-370

Staniland IJ, Boyd IL, Reid K (2004) Comparing individual and spatial influences on foraging behaviour in Antarctic fur seals. Mar Ecol Prog Ser 275:263-274

Thompson PM, Ollason JC (2001) Lagged effects of ocean climate change on fulmar population dynamics. Nature 413:417-420

Tollit DJ, Steward MJ, Thompson PM, Pierce GJ, Santos MB, Hughes S (1997) Species and size differences in the digestion of otoliths and beaks: implications for estimates of pinniped diet composition. Can J Fish Aquat Sci 54: 105-119

Tollit DJ, Wong M, Winship AJ, Rosen DAS, Trites AW (2003) Quantifying errors associated with using prey skeletal structures from fecal samples to determine the diet of Steller's sea lion (Eumetopias jubatus). Mar Mamm Sci 19: $724-744$

Wamberg S, Olesen CR, Hansen HO (1992) Influence of dietary sources of fat on lipid-synthesis in mink (Mustela vison) mammary tissue. Comp Biochem Physiol A 103:199-204

Submitted: November 24, 2003; Accepted: February 23, 2005 Proofs received from author(s): May 16, 2005 